\title{
ANEXO: DOCUMENTO "PROPOSICIONES"
}

FhHowItIRE

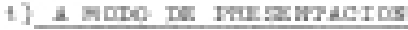

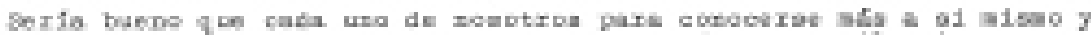

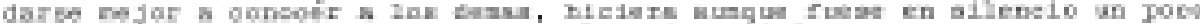

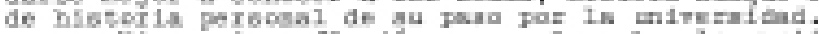

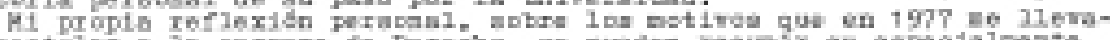

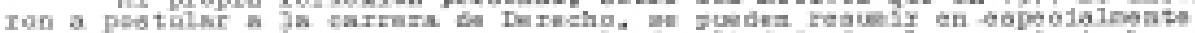

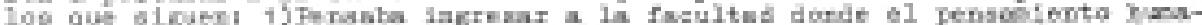

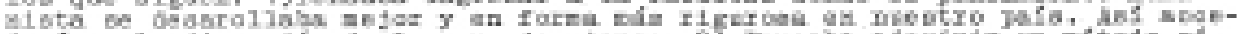

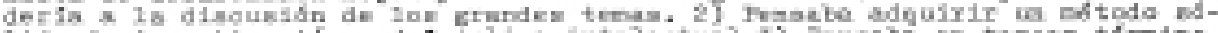

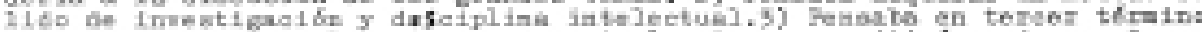

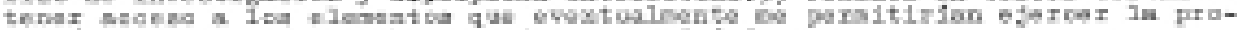

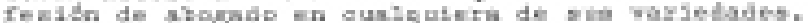

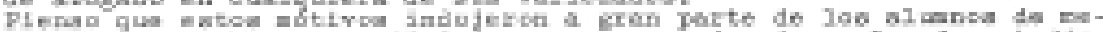

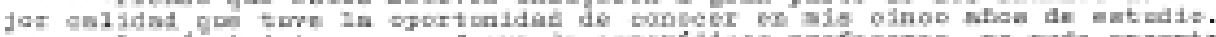

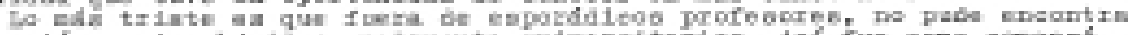

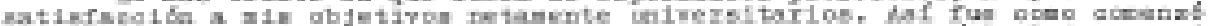

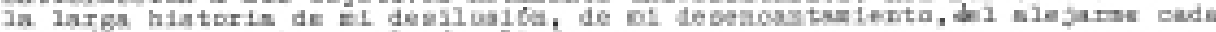
Twa

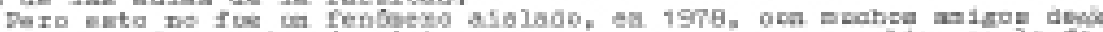

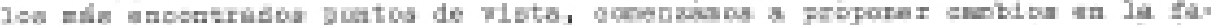

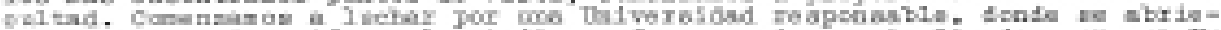

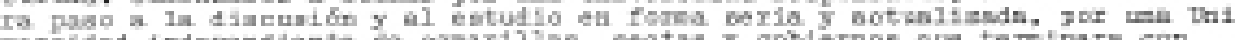

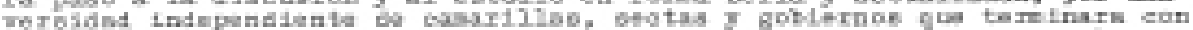

I.F

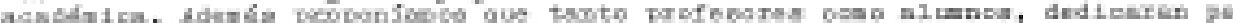

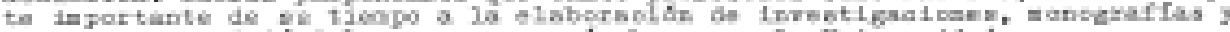

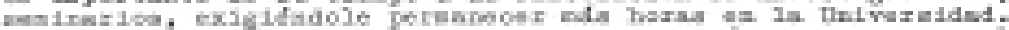

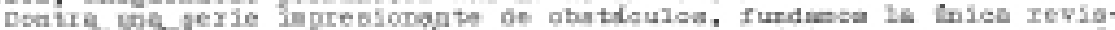

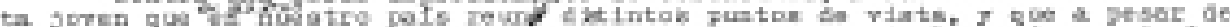

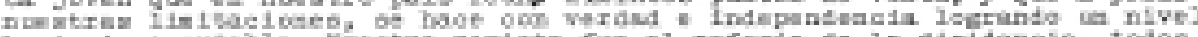

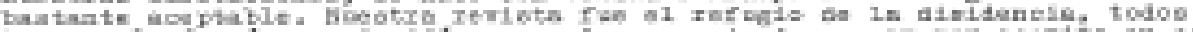

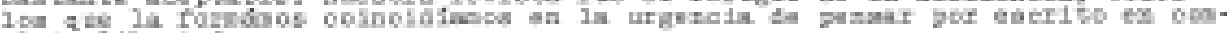

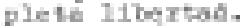

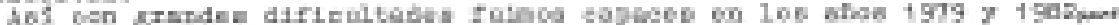

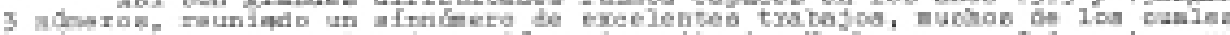

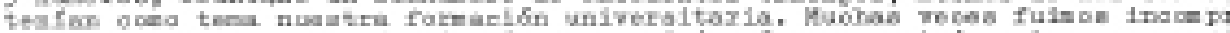

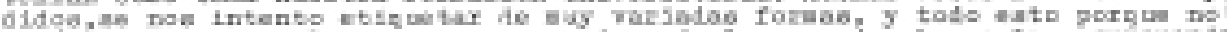

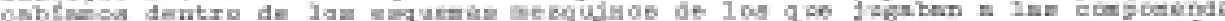

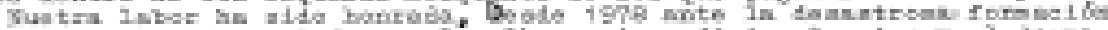

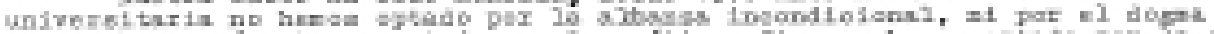

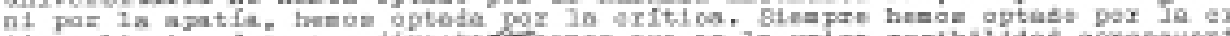

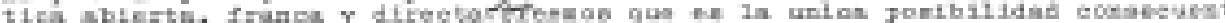

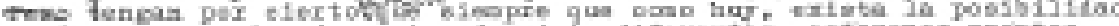

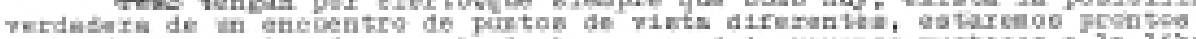

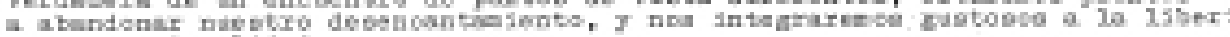

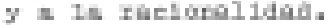

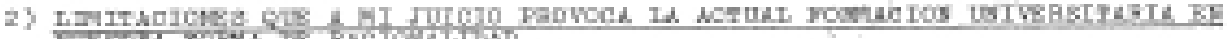

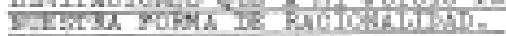

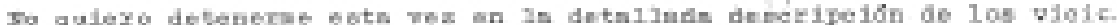

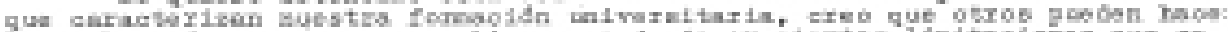

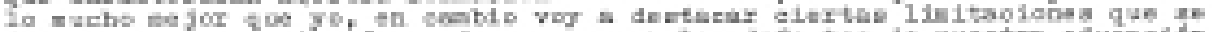

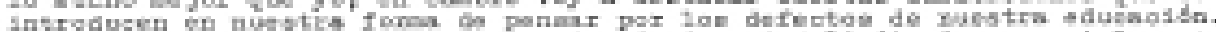

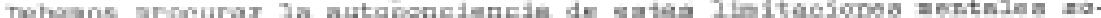

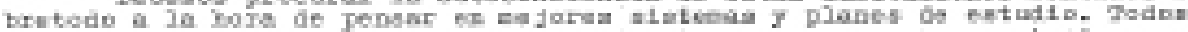

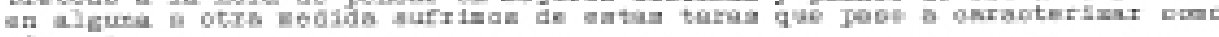
-

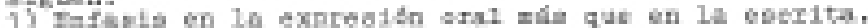

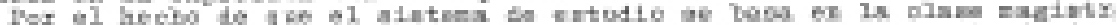

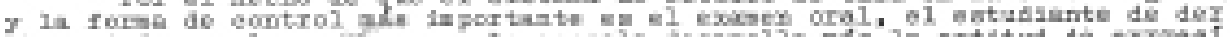

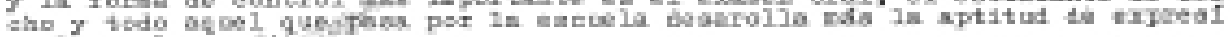

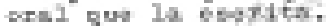

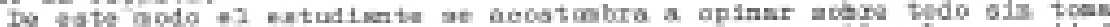

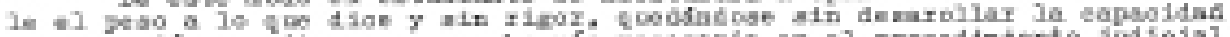

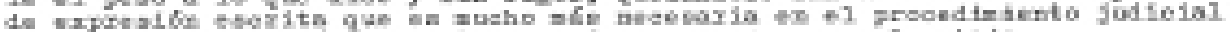

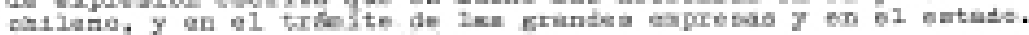

- 


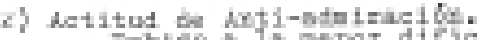

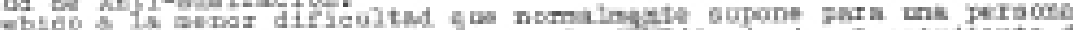

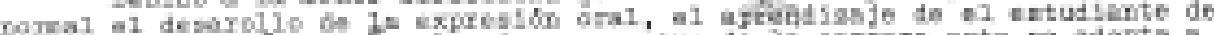
Wholo

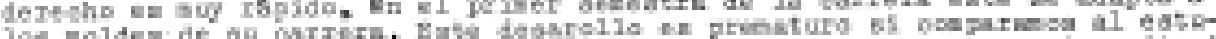

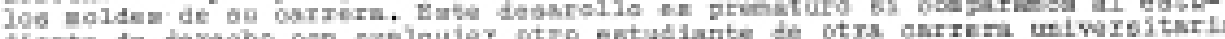

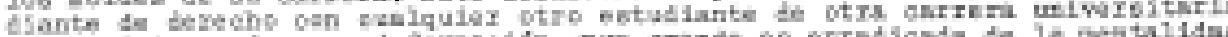

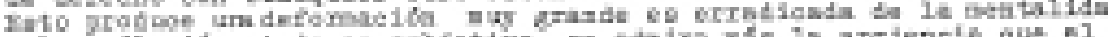

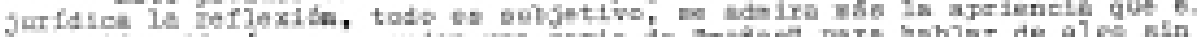

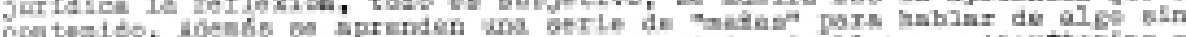

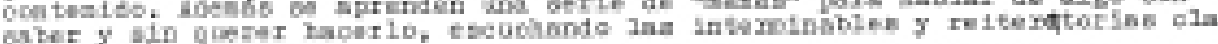

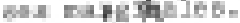

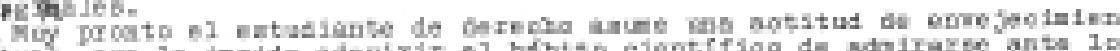

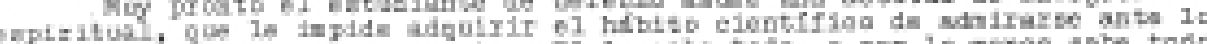

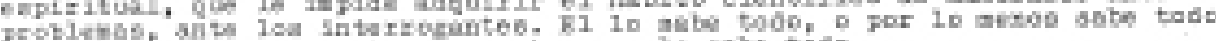

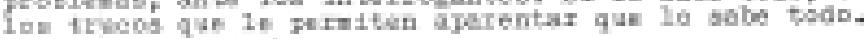

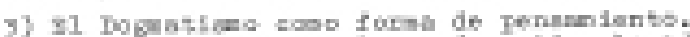

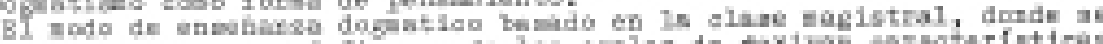

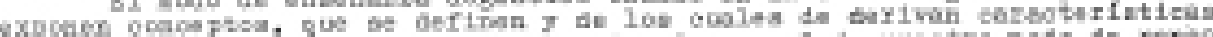

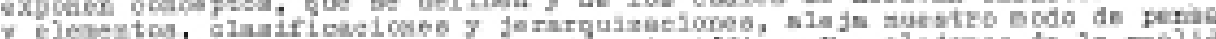

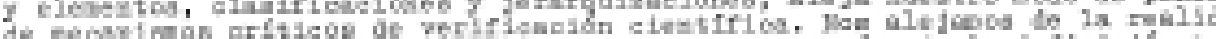

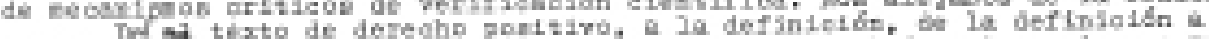

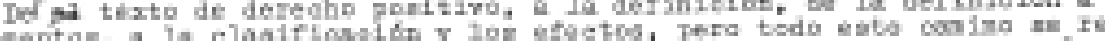

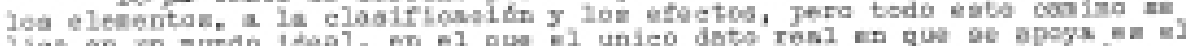

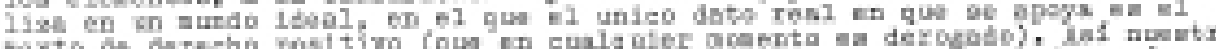

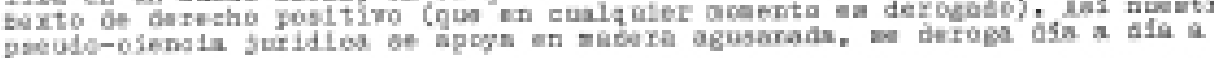
国1 ing.

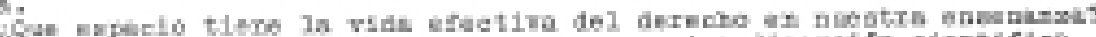

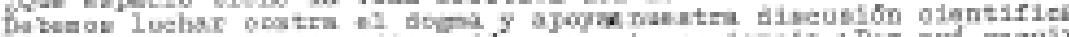

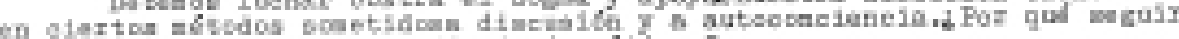

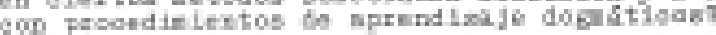

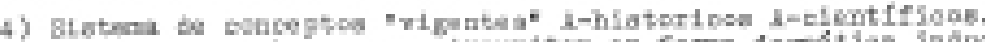

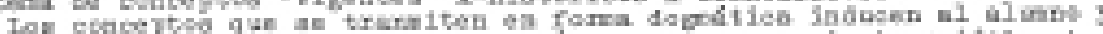

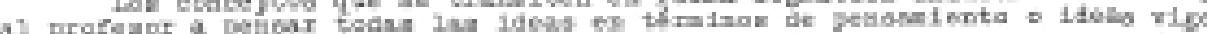

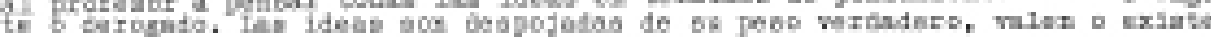

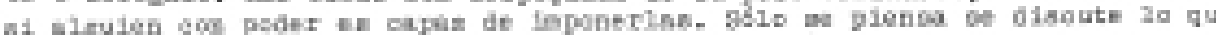

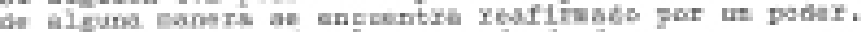

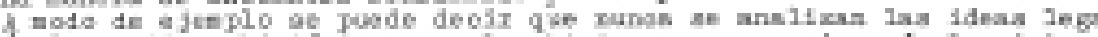

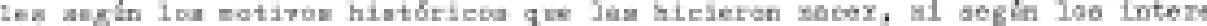

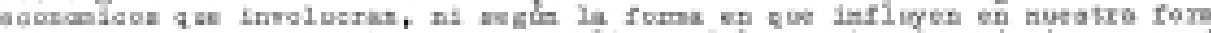

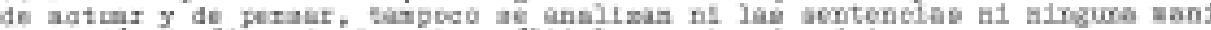

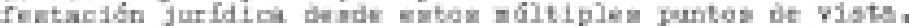

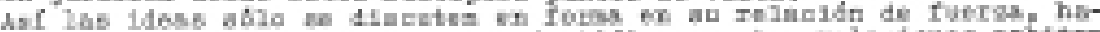

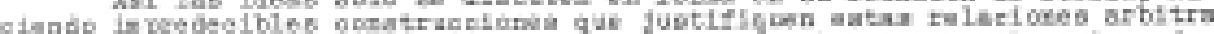

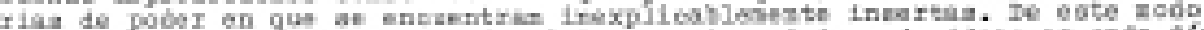

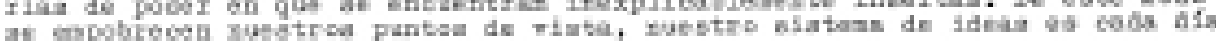
nen mipe

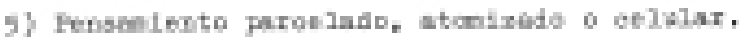

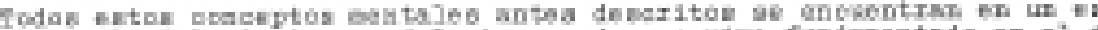

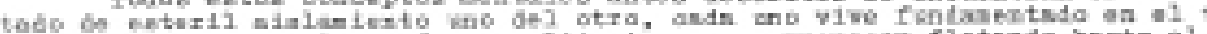

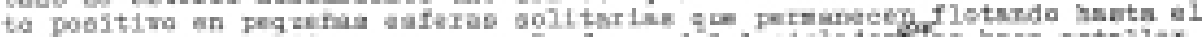

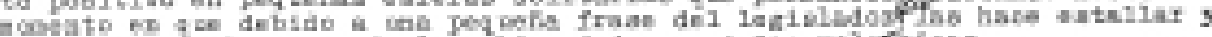

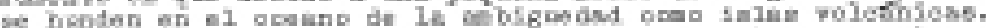

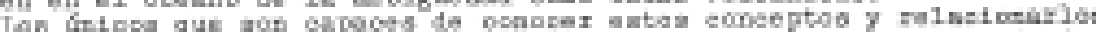

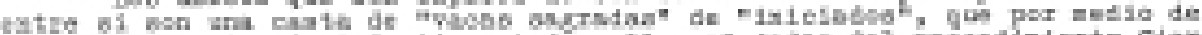
ojrutso J enda da

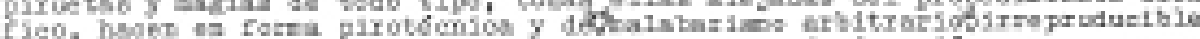

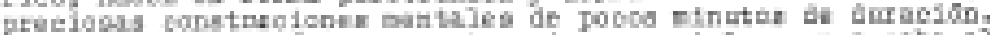

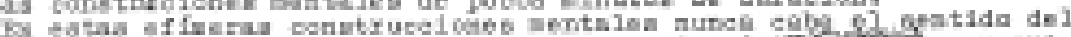

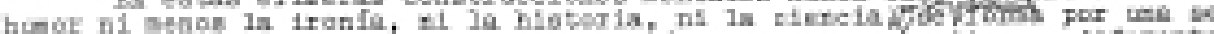

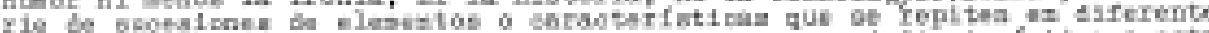

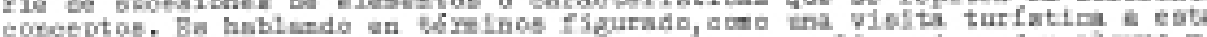

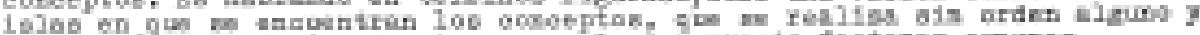

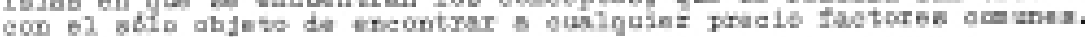

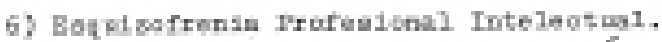

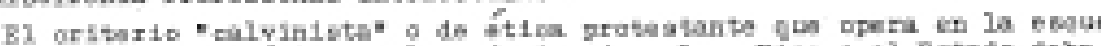

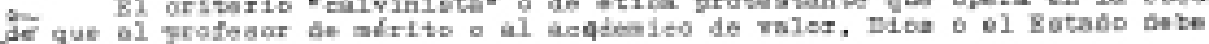




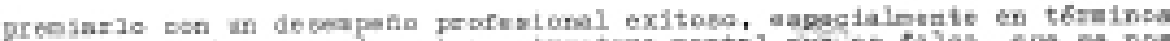

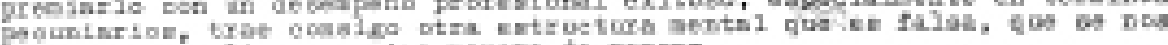

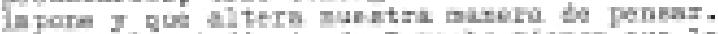

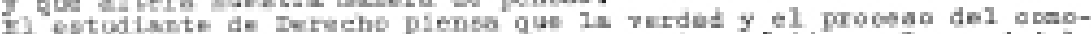

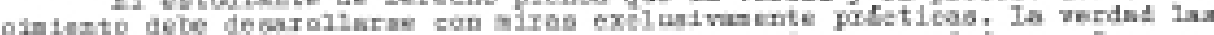

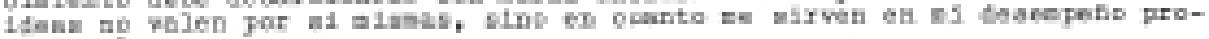
foritionis

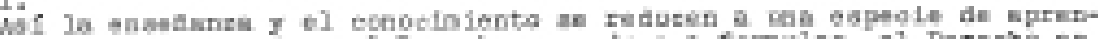

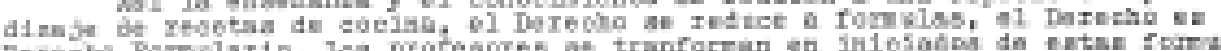

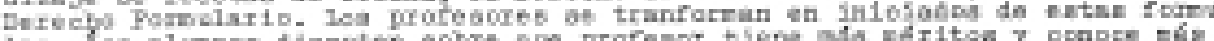

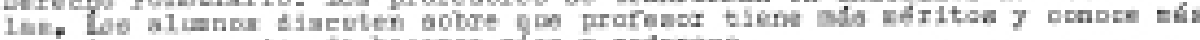

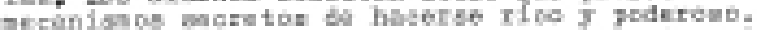

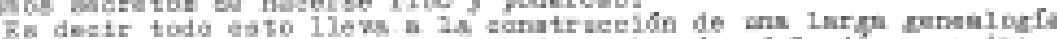

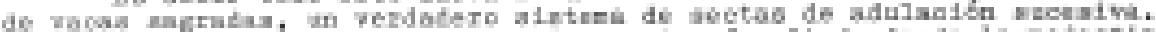

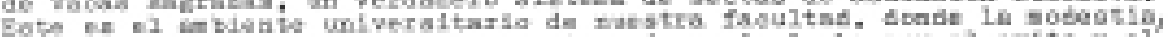

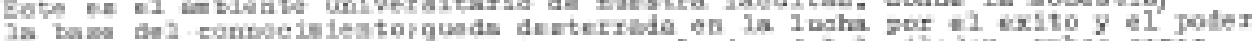

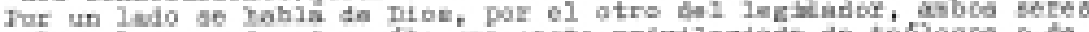

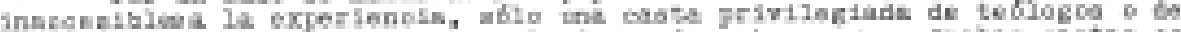

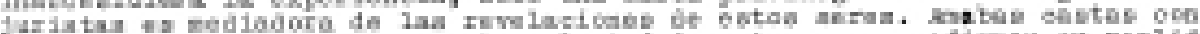

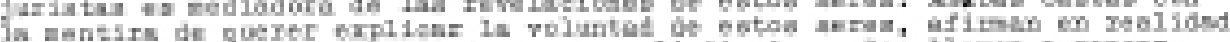

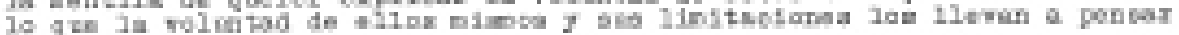

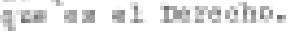

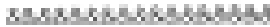

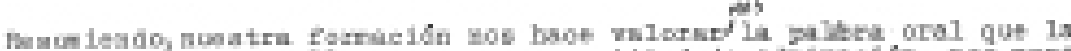

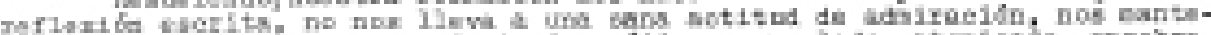

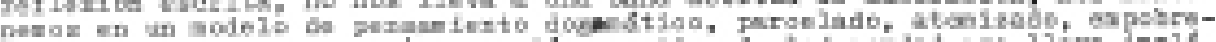

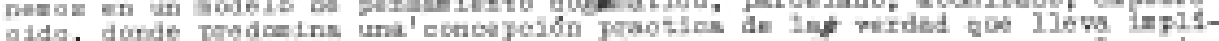

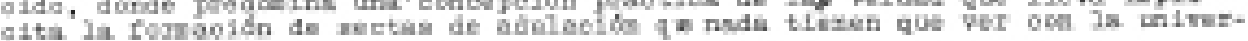
ildind.

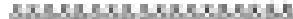

\section{L-110}

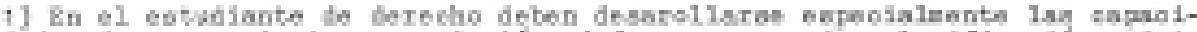

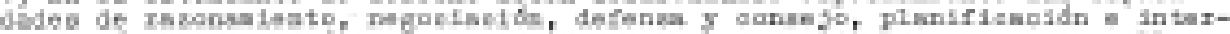

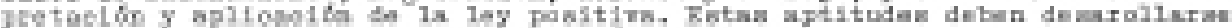

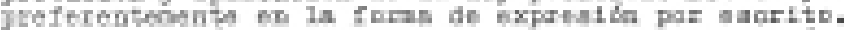

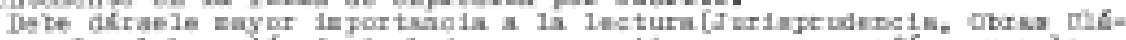

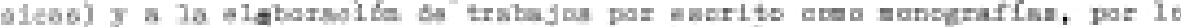

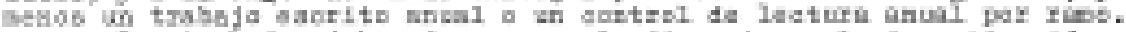

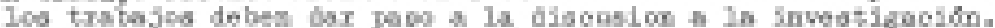

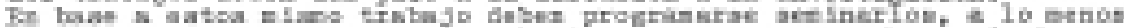

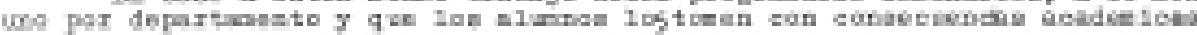

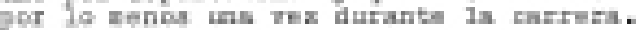

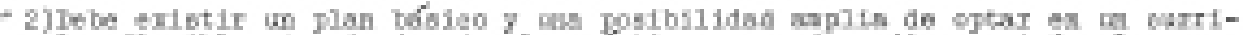

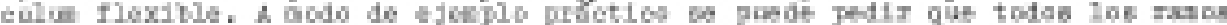

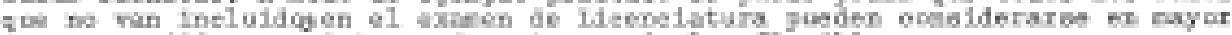

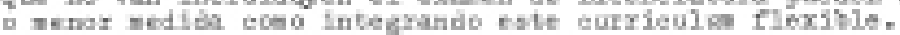

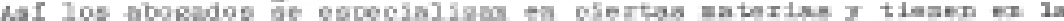

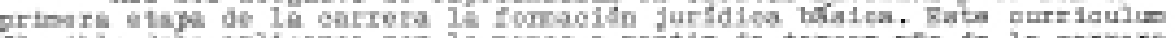

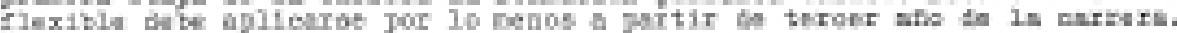

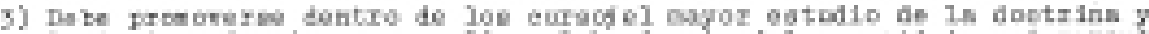

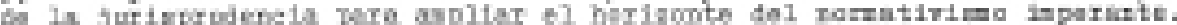

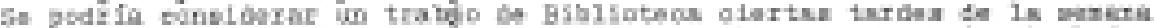

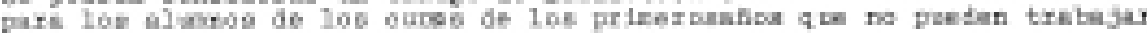
tediriti

5"

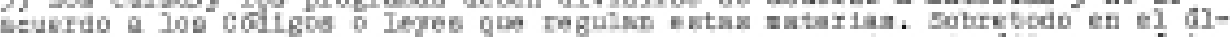

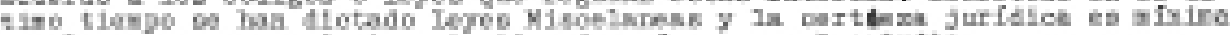

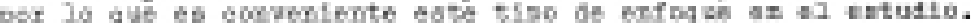

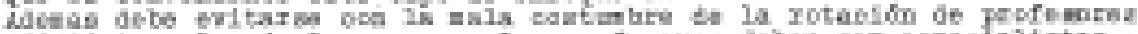

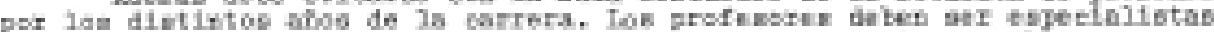

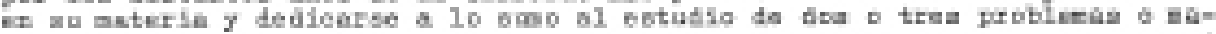

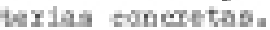




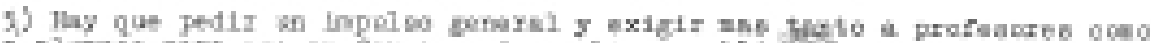

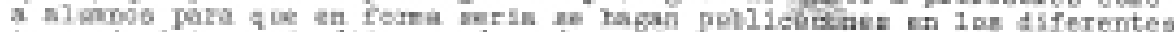

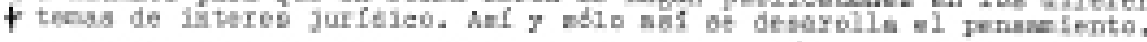

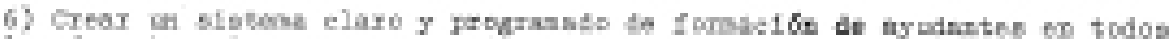

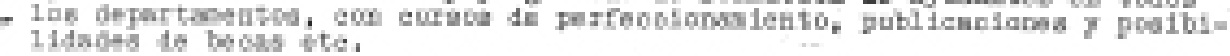

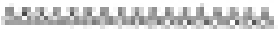

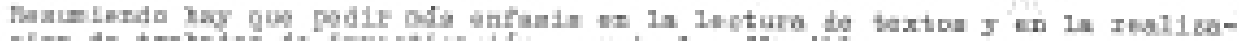

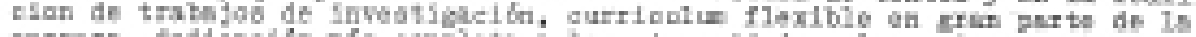

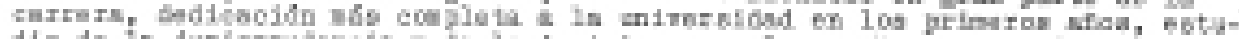

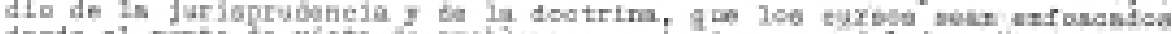

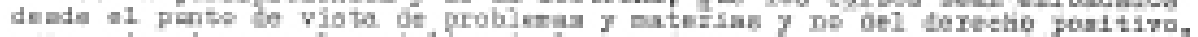

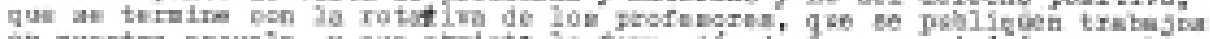

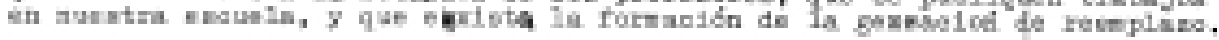

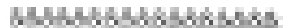

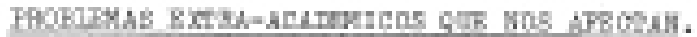

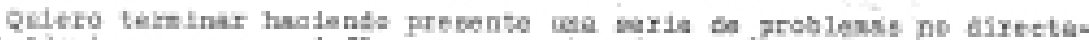

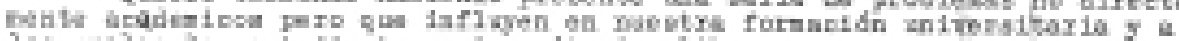

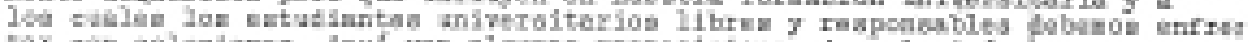

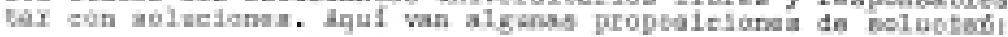

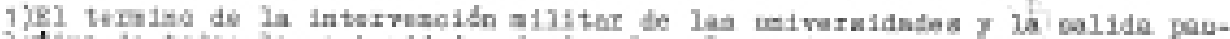

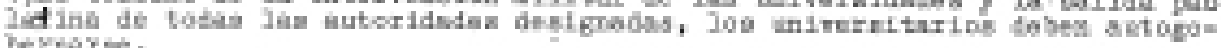
Dothisto

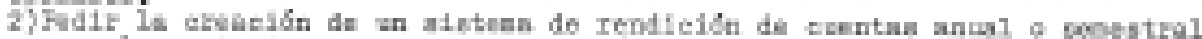

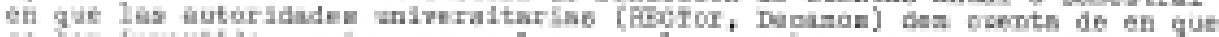

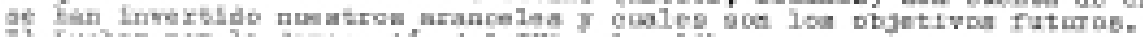

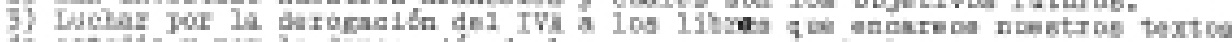

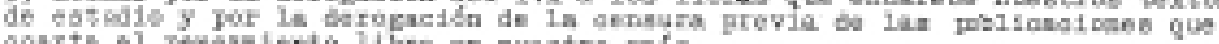

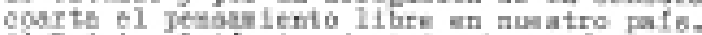

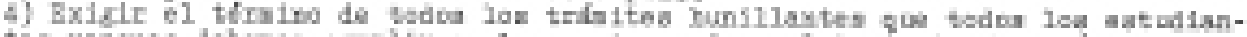

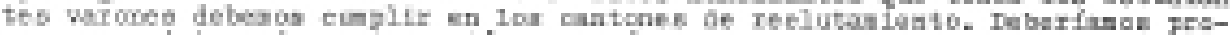

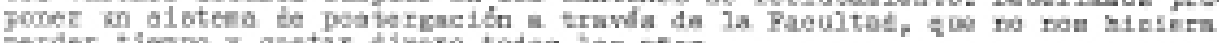

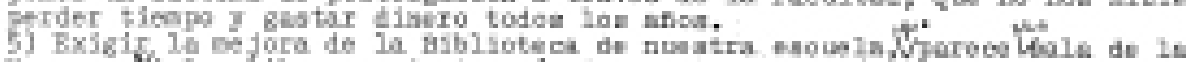

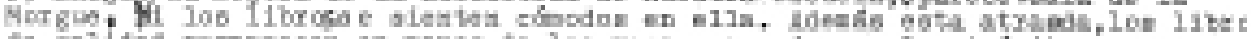

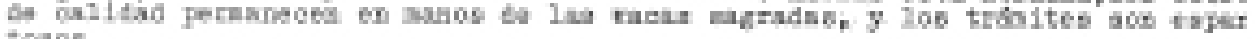
tevan.

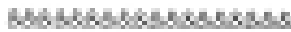

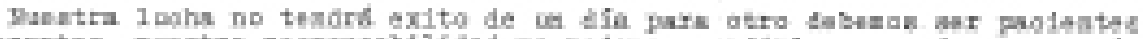

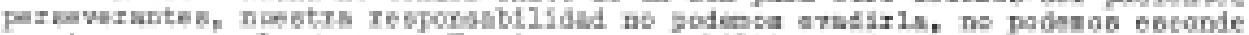

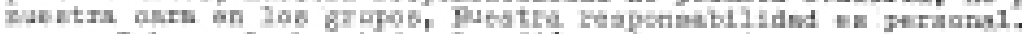

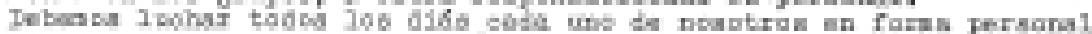

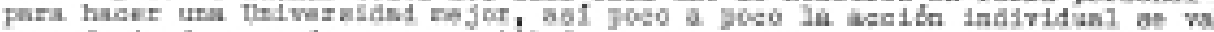

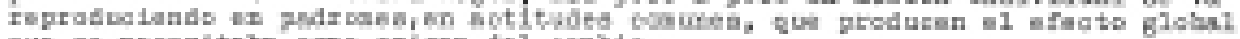

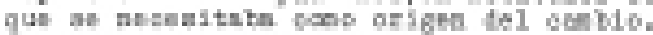

